\title{
Analysis of periarticular bone changes in patients with cutaneous psoriasis without associated psoriatic arthritis
}

\author{
David Simon, ${ }^{1}$ Francesca Faustini, ${ }^{1}$ Arnd Kleyer, ${ }^{1}$ Judith Haschka, ${ }^{1,2}$ \\ Matthias Englbrecht, ${ }^{1}$ Sebastian Kraus, ${ }^{1}$ Axel J Hueber, ${ }^{1}$ Roland Kocijan, ${ }^{1,2}$ \\ Michael Sticherling, ${ }^{3}$ Georg Schett, ${ }^{1}$ Jürgen Rech ${ }^{1}$
}

\begin{abstract}
Handling editor Tore K Kvien
${ }^{1}$ Department of Internal

Medicine 3, Rheumatology and Immunology, University of

Erlangen-Nuremberg, Erlangen, Germany

${ }^{2}$ Medical Department II, the VINFORCE Study Group,

St. Vincent Hospital, Academic Teaching Hospital of Medical University of Vienna, Vienna, Austria

${ }^{3}$ Department of Dermatology, University of ErlangenNuremberg, Erlangen, Germany
\end{abstract}

\section{Correspondence to}

Dr Juergen Rech, Department of Internal Medicine 3,

Rheumatology and Immunology, University of Erlangen-Nuremberg, Ulmenweg 18, Erlangen 91054, Germany; juergen.rech@uk-erlangen.de

Received 24 July 2014 Revised 25 November 2014

Accepted 13 January 2015

Published Online First

4 February 2015

\section{ABSTRACT}

Objectives To search for structural bone changes in the joints of psoriasis patients without psoriatic arthritis (PsA).

Methods 55 psoriasis patients without any current or past symptoms of arthritis or enthesitis and 47 healthy controls were examined by high-resolution peripheral quantitative CT scans of the metacarpophalangeal joints. Number, size and exact localisation of erosions and enthesiophytes were recorded by analysing axial scans of the metacarpal heads and phalangeal bases and were confirmed in additional coronal and/or sagittal sections. In addition, we collected demographic and clinical data including subtype, duration and severity of psoriasis. Results Psoriasis patients showed a larger and significantly increased number of enthesiophytes (total number 306; mean \pm SD/patient 5.62 \pm 3.30 ) compared with healthy controls (total number 138; mean \pm SD/ patient 3.04 $\pm 1.81, p<0.001)$. Enthesiophytes were typically found at the dorsal and palmar sides of the metacarpal heads where functional entheses related to extensor and flexor tendons are localised. Bone erosions were rare and not significantly different between psoriasis patients and healthy controls. If present, erosions were almost exclusively found at the radial side of the second metacarpal head in both psoriasis patients and healthy controls.

Conclusions Psoriasis patients without PsA show substantial signs of enthesiophyte formation compared with healthy controls. These changes represent new bone formation at mechanically exposed sites of the joint and substantiate the concept of the existence of a 'Deep Koebner Phenomenon' at enthesial sites in psoriasis patients.

\section{INTRODUCTION}

The spectrum of psoriatic disease comprises three major entities, skin disease, psoriatic arthritis (PsA) and psoriatic nail disease. ${ }^{1}$ Skin disease is substantially more common (2\%-3\%) than PsA, whose prevalence is considered ranging from $0.3 \%$ to $1.0 \%$. $^{2}$ Some $39 \%$ of patients with psoriasis have PsA in hospital settings and some $11 \%$ in the community. ${ }^{3}{ }^{4}$ In the majority of cases (up to $60 \%$ ), ${ }^{5}$ skin disease is reported to predate arthritis while in the remaining cases it can precede or concomitantly start with skin disease. Diagnosis of PsA requires the presence of clinical signs of musculoskeletal disease, such as arthritis, enthesitis or inflammatory back pain. Also, Classification Criteria for Psoriatic Arthritis (CASPAR) criteria for the classification of PsA $^{6}$ explicitly mention that for classification of PsA, clinical signs of inflammation have to be present. Whereas the term PsA is reserved for clinical manifestations of psoriatic disease affecting the musculoskeletal system, discrete subclinical changes in the joints and the entheses may occur before the onset of PsA and/or may affect a larger proportion of patients with psoriatic skin disease. This concept would also suggest an even tighter link between the skin and the joints in psoriatic disease, representing two organ manifestations of the same underlying disease process. Support for this notion comes from imaging studies providing evidence for the existence of subclinical inflammatory changes in patients with psoriatic skin disease using MRI or high-resolution ultrasound scans. ${ }^{7-9}$ It has to be defined, however, if such changes really impact on joint architecture in psoriasis patients. Furthermore, in contrast to rheumatoid arthritis (RA), inflammation may not be the only responsible factor for articular changes in psoriatic disease but biomechanical factors related to entheseal stress may substantially contribute to the disease as well.

That PsA is accompanied by changes of the joint structure is well described. ${ }^{10-13}$ However, whether such changes are found even in patients with psoriatic skin disease without PsA is currently partially explored. ${ }^{14}$ One key aspect of structural changes in PsA is new bone formation, which strikingly differs from what is observed in RA and particularly affects the entheseal regions of the joints (enthesiophytes). ${ }^{13}$ Recent work has identified entheseal pathology as a specific part of the PsA disease process. Entheses may represent the primary site of musculoskeletal changes in psoriasis patients developing PsA. In particular, the understanding of entheseal structures as an organ with a high degree of structural and functional organisation and the coining of the term 'synovio-entheseal complex' have extended our view on PsA. ${ }^{15-17}$ These concepts are of potential importance in searching for the discrete changes of the joints in patients with psoriatic skin disease.

The aim of this work was to investigate the skeletal micro-architecture of the joints in psoriasis patients with skin disease but no evidence for PsA 
and compare it with healthy controls. We thereby particularly focused on searching for signs of new bone formation and erosions in psoriasis patients considering that mechanically exposed areas of the joints may show signs of structural changes even in the absence of PsA. Therefore, a comprehensive analysis of enthesiophytes as well as bone erosions was carried out in patients with psoriatic skin but not joint disease and compared with the results obtained in healthy controls.

\section{METHODS}

\section{Patients' recruitment and clinical assessment}

Between October 2012 and October 2013, all psoriasis patients without a clinical diagnosis of PsA according to the CASPAR criteria $^{6}$ followed at the Dermatology Department of the University of Erlangen-Nuremberg were consecutively referred to the Rheumatology Department of the same institution for detailed bone analysis. An experienced rheumatologist examined the patients for the presence of clinical signs of musculoskeletal involvement (synovitis, enthesitis, dactylitis and/or inflammatory back pain). Patients with no current or previous evidence for arthritis or enthesitis or other manifestations of PsA were selected to undergo further evaluation. Those who had musculoskeletal presentations were excluded from the present study. In the remaining 55 psoriasis patients, demographic data such as age, sex, height, body weight, body mass index (BMI) and smoking status were collected and disease specific characteristics such as disease severity of psoriasis (Psoriasis Area Severity Index; PASI), ${ }^{18}$ disease duration and psoriasis subtype including nail and scalp involvement were also recorded. Quality of life parameters were assessed using the Dermatology Life Quality Index (DLQI) questionnaire. ${ }^{19} \mathrm{C}$ reactive protein (CRP) levels $(\mathrm{mg} / \mathrm{L})$ and presence of rheumatoid factor $(\mathrm{RF})$ and anticyclic citrullinated peptide antibodies (ACPA) were measured. Current treatments including topic and systemic antipsoriasis drugs were recorded in all patients. In addition to the psoriasis patients, 47 healthy controls with comparable age and sex were also investigated. Healthy controls were taken randomly from a historical cohort of healthy men and women with no signs of inflammatory or autoimmune disease as well as no personal or family history of such a disease who participated in a bone analysis by high-resolution peripheral quantitative CT (HR-pQCT). The study was conducted upon approval of the local ethic committee of the University of Erlangen and with the authorisation of the National Radiation Safety Agency (Bundesamt für Strahlenschutz). Each patient provided informed consent.

\section{High-resolution peripheral quantitative CT}

Psoriasis patients and healthy controls underwent HR-pQCT scans of the metacarpophalangeal joints (MCPs) 2 and 3 through an XtremeCT scanner (SCANCO Medical, Brütisellen, Switzerland). Correct positioning of the hand was ensured by the use of a custom holder to reduce movement artefacts. Resolution was of $82 \mu \mathrm{m}$ isotropic voxels. Scanning of the MCP region extended between 80 slices distal to the edge of the third metacarpal head $(\mathrm{MCH})$ and 242 slices proximal to it, with a scanning time of $8.4 \mathrm{~min}$. The definition of the region of interest (ROI) allowed the visualisation of the portions of the $\mathrm{MCH}$ and the phalangeal base $(\mathrm{PB})$ comprised in the articular space and those thin portions located in the immediate vicinity of it as delimited by the insertion of the articular capsule (periarticular bone) (figure 1).

\section{Detection and localisation of erosions and enthesiophytes}

As in previous works, erosions were defined as breaks in the cortical shell visible into two planes. ${ }^{20}$ Sites of new bone formation within the limits of the above defined ROI were referred to as enthesiophytes, when found at the insertion sites of tendons, ligaments or capsule, or at the locations of functional entheses. As described by others, ${ }^{21}$ these areas are present in the MCP joints at the dorsal side, where the extensor tendon wraps around the $\mathrm{MCH}$ and is pressed against it during finger flexion. In the areas of functional entheses, the tendon is provided with a sesamoid fibrocartilage that is located within the joint space in direct contact with the periosteal cartilage of the bone. ${ }^{16}{ }^{21} \mathrm{At}$ the palmar aspect, a specialised thickened part of the capsule,
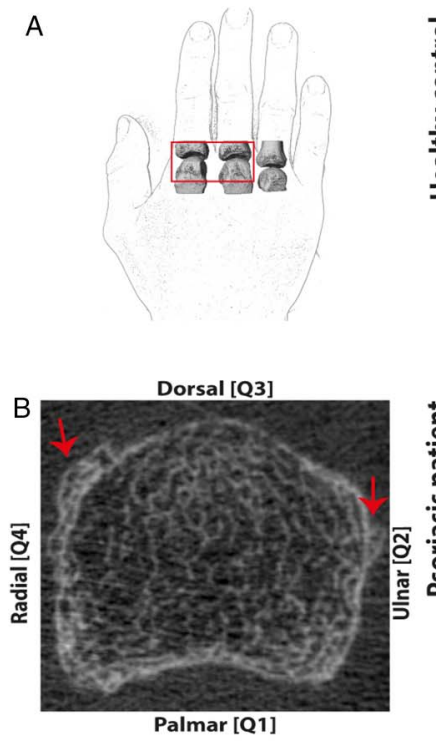
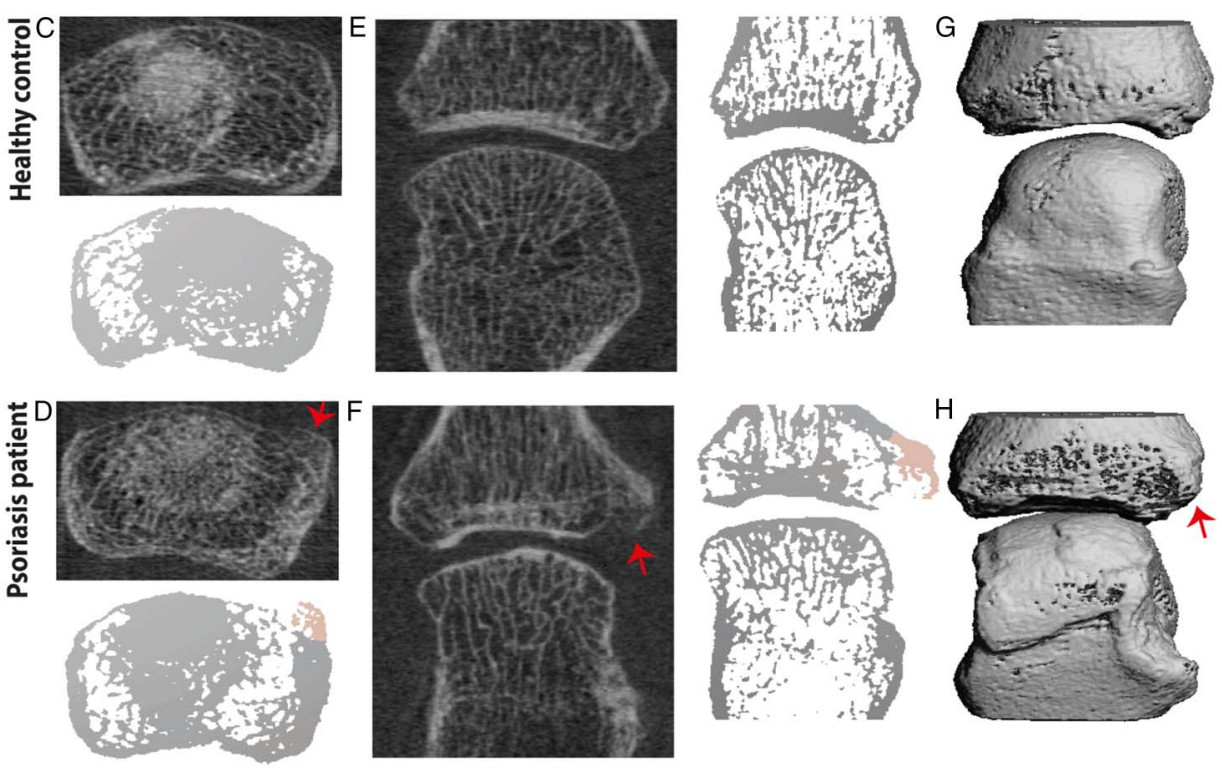

Figure 1 Region of interest (ROI) and examples of periarticular bone changes in psoriasis patients and healthy controls. (A) 3D view of the ROI. (B) Distribution of the axial quadrants and examples of enthesiophytes (red arrows). (C and D) Axial, (E and F) sagittal and (G and H) 3D reconstruction (dorsal view) of a metacarpophalangeal joint in a healthy control (upper row, $C, E$ and $G$ ) and a psoriasis patient (lower row, $D$, $F$ and $\mathrm{H}$ ) showing an enthesiophyte (red arrows) at the insertion of the collateral ligament at the phalangeal base. 
the palmar plate, contributes to maintaining the flexor tendon in its position preventing the hyperextension of the joint.

\section{Image analysis}

Images were analysed using axial slices $(\mathrm{N}=322)$. For each axial slice, the imaged bone was subdivided into four quadrants distributed at the palmar (Q1), ulnar (Q2), dorsal (Q3) and radial (Q4) side, respectively, ${ }^{20}$ so that the exact localisation of each detected erosion and enthesiophyte could be defined. To confirm each lesion, a perpendicular reconstruction either coronal or sagittal was used. For each joint, the $\mathrm{MCH}$ and $\mathrm{PB}$ were considered as separate entities and referred to as compartments. Therefore, for each patient, four compartments were imaged corresponding to $\mathrm{MCH} 2, \mathrm{~PB} 2, \mathrm{MCH} 3$ and $\mathrm{PB} 3$. When lesion count per compartment is described, the number of lesions ensued from the sum of lesions of each axial quadrant, which was then confirmed in the perpendicular plane. When more than one erosion was visible in a single quadrant, the largest one was chosen in order to carry out the measurement of its volume. We refer to the largest visible erosion in each quadrant as target erosion. The volume $\left(\mathrm{mm}^{3}\right)$ assessment of the latter lesion was obtained applying the half-ellipsoid formula as previously described. ${ }^{22}$ As for the assessment of erosions, enthesiophytes number was assessed in each quadrant and for each quadrant the biggest visible lesion (target enthesiophyte) was measured to determine its maximal height. Enthesiophyte height was defined as the distance between the highest surface of the lesion and the original surface of the cortical bone and measured in millimetres. ${ }^{1320}$ All images were once evaluated by two independent and blinded readers (DS, SK). Imaging analysis and measurements were performed through the open source DICOM viewer Osirix V.4.1 (Rosslyn, Virginia, USA). Additional bidimensional and tridimensional images were obtained through the 3D image software provided by the manufacturer. The latter are used only for illustrative purposes in this paper.

\section{Statistical analysis}

Data were collected, organised and analysed through SPSS software for statistics (IBM SPSS V.21.0, IBM corporation, Armonk, New York, USA). In general, continuous variables are described as mean $\pm S D$, and categorical variables are provided as numbers and percentages. Age and sex distribution were compared in the two examined groups. For age, after testing for Gaussian distribution by the Kolmogorov-Smirnov test, a t test for independent samples was carried out in order to compare the mean values of the variable. Differences in sex distribution between the two groups were assessed through $\chi^{2}$ test. Number and volume of erosions, number and height of enthesiophytes were compared in psoriasis patients and healthy controls. After testing for Gaussian distribution, Mann-Whitney U test or t test was applied as appropriate. In addition, a linear regression model was carried out with the total number of enthesiophytes being the dependent variable, while BMI and the grouping variable (psoriasis patients vs healthy individuals) were entered as independent variables. For image reading, agreements of the two independent readers were assessed using Cohen's $\kappa$ coefficient for semiquantitive assessment and bivariate correlation for number and size measurements (enthesiophytes). When appropriate, bivariate correlation after testing for Gaussian distribution was applied.

\section{RESULTS}

Demographic and clinical features of the psoriasis patients

A total of 55 psoriasis patients and 47 healthy controls were enrolled into this study. Mean age and sex distribution were comparable between the two groups: mean age was $49.0 \pm 11.4$ in psoriasis patients and $45.7 \pm 12.9$ years in healthy controls $(\mathrm{t}=1.38, \mathrm{p}=0.17)$. In all, 20 out of 55 psoriasis patients (36.4\%) and 23 out of 47 healthy controls (48.9\%) were women $\left(\chi^{2}(1)=1.643, p=0.20\right)$. As expected, psoriasis patients showed a higher BMI compared with the healthy controls $(27.9 \pm 5.6$ vs $25.0 \pm 4.7$, respectively, $U=566.5, Z=$ -2.94, $\mathrm{p}=0.003)$. The main demographic and clinical characteristics of psoriasis patients are summarised in table 1. Disease duration was $15.2 \pm 15.4$ years in psoriasis patients. The most common subtype was psoriasis vulgaris $(72.7 \%)$. Nail involvement was present in $50.9 \%$, and scalp involvement in $29.1 \%$ of the patients. Disease severity, assessed by PASI, was $6.2 \pm 8.0$ and its average effect on patients' quality of life, assessed by the DLQI, was moderate (mean score 6.3 \pm 6.1 ). None of the tested patients showed ACPA positivity or had high-titre RF (>50 IE/mL), while four patients $(7.3 \%)$ had low-titre RF $(25.5 \pm 9.3 \mathrm{IE} / \mathrm{mL})$. Systemic inflammation markers, such as CRP, were within the normal range. With respect to the treatment regimen, $15(27.3 \%)$ patients were not receiving treatment, while $25(45.5 \%)$ were under topical therapies, $11(20.0 \%)$ were treated with fumaric acid, 9 $(16.4 \%)$ were treated with systemic agents alone or in association with the previously mentioned treatments, 3 (5.5\%) patients were receiving TNF-alpha inhibitor (TNF-i) and 1 $(1.8 \%)$ patient was under ustekinumab.

Table 1 Demographic and disease specific characteristics

\begin{tabular}{|c|c|c|}
\hline & Psoriasis patients & Healthy controls \\
\hline \multicolumn{3}{|l|}{ Demographic characteristics } \\
\hline $\mathrm{N}$ of subjects & 55 & 47 \\
\hline Sex (male/female) & $35 / 20$ & $24 / 23$ \\
\hline Age (years) & $49.0 \pm 11.4$ & $45.7 \pm 12.9$ \\
\hline Height $(\mathrm{cm})$ & $174.2 \pm 9.3$ & $174.0 \pm 10.4$ \\
\hline Weight $(\mathrm{kg})$ & $84.9 \pm 20.1$ & $78.0 \pm 18.4$ \\
\hline BMI & $27.9 \pm 5.6$ & $25.0 \pm 4.7$ \\
\hline Smokers N (\%) & $16(29.1)$ & $11(23.4)$ \\
\hline \multicolumn{3}{|l|}{ Disease specific characteristics } \\
\hline Duration of skin psoriasis (years) & $15.2 \pm 15.4$ & - \\
\hline PASI & $6.2 \pm 8.0$ & - \\
\hline DLQI & $6.3 \pm 6.1$ & - \\
\hline \multicolumn{3}{|l|}{ Phenotypic characteristics } \\
\hline Psoriasis vulgaris N (\%) & $40(72.7)$ & - \\
\hline Other subtypes $\mathrm{N}(\%)$ & $15(27.3)$ & - \\
\hline Nail involvement $\mathrm{N}(\%)$ & $28(50.9)$ & - \\
\hline Scalp involvement N (\%) & $16(29.1)$ & - \\
\hline \multicolumn{3}{|l|}{ Other clinical characteristics } \\
\hline ACPA positive $\mathrm{N}(\%)$ & 0 & - \\
\hline RF positive $\mathrm{N}(\%)^{*}$ & $4(7.3)$ & - \\
\hline $\mathrm{C}$ reactive protein $(\mathrm{mg} / \mathrm{L}) \dagger$ & $3.8 \pm 4.6$ & - \\
\hline \multicolumn{3}{|l|}{ Treatment modalities } \\
\hline No current treatment $\mathrm{N}(\%)$ & $15(27.3)$ & - \\
\hline Topical therapies $\mathrm{N}(\%)$ & $25(45.5)$ & - \\
\hline Fumaric acid $\mathrm{N}(\%)$ & $11(20.0)$ & - \\
\hline Systemic agents $\mathrm{N}(\%)$ & $9(16.4)$ & - \\
\hline TNF-i N (\%) & $3(5.5)$ & - \\
\hline Ustekinumab N (\%) & $1(1.8)$ & - \\
\hline \multicolumn{3}{|c|}{$\begin{array}{l}\text { *All four patients had low-titre } \mathrm{RF} \text { ( }<50 \mathrm{IE} / \mathrm{mL} \text { ). } \\
\text { †Normal value }<5 \mathrm{mg} / \mathrm{mL} \text {. } \\
\text { ACPA, anticyclic citrullinated peptide antibodies; BMI, body mass index; DLQI, } \\
\text { Dermatology Life Quality Index; RF, rheumatoid factor. }\end{array}$} \\
\hline
\end{tabular}




\section{Comparative analysis of enthesiophytes in the psoriasis patients and healthy controls}

The number of enthesiophytes was evaluated in each axial quadrant in each assessed joint compartment. The total number of enthesiophytes was 306 in the psoriasis patient group and 138 in the healthy control group. The average number of enthesiophytes per patient in psoriasis patients and healthy controls accounted for six (mean \pm SD 5.62 \pm 3.30$)$ and three (mean $\pm S D$ $3.04 \pm 1.81, \mathrm{U}=602.5, \mathrm{Z}=-4.444, \mathrm{p}<0.001$ ), respectively. The majority of the lesions were found at the MCHs, predominantly on the $\mathrm{MCH} 2$, and the distribution was similar in both psoriasis patients and healthy controls (see figure 2). With respect to anatomical quadrants, enthesiophytes did not show the same pattern of distribution as observed for erosions (see below). Hence, distribution of enthesiophytes was wider than one of the erosions, including functional entheses such as the dorsal $\mathrm{MCHs}$, but also classical enthesial sites such as the palmar $\mathrm{MCH}$ and dorsal PB (figures 2 and 3). When assessing the size of enthesiophytes, we found that the lesions in psoriasis patients were significantly larger in each of the compartments than in healthy controls (table 2), suggesting that the overall burden of enthesiophytes in psoriasis patients is significantly higher than in healthy controls.

Furthermore, we carried out a linear regression model, with enthesiophytes as the dependent and BMI as well as grouping (psoriasis patients vs healthy individuals) as independent variables. This model showed that psoriasis is independently associated with a larger total number of enthesiophytes in comparison with healthy participants $(\beta=-0.34, \mathrm{t}=-3.22$, $\mathrm{p}=0.002)$. Adding age and gender to the model did not change the outcome for groups $(\beta=-0.31, t=-2.87, p=0.005)$. When defining the impact of nail disease in the development of enthesiophytes within the psoriasis patient group, we did not find any significant difference in the mean number of enthesiophytes between psoriasis patients with and without nail disease (5.77 \pm 3.65 vs $5.39 \pm 2.99, U=363.0, Z=-0.02, p=0.99$ ). Similarly, we did not find a significantly higher mean number of enthesiophytes in patients with scalp involvement (patients with no scalp involvement $5.61 \pm 3.49$ vs $5.62 \pm 2.39, \mathrm{U}=297.0, \mathrm{Z}=$ $-0.28, \mathrm{p}=0.78)$.

\section{Comparative analysis of bone erosions in the psoriasis patients and healthy controls}

In the 55 psoriasis patients, 27 bone erosions were identified in the MCPs, while 18 were identified in the healthy controls.
The cumulative frequency of erosions in the two groups did not differ significantly between psoriasis patients and healthy controls, although numerically more erosions were found in psoriasis patients. When detected, erosions mostly involved the MCHs of the respective joints, with a similar distribution observed in the psoriasis patients and healthy controls (table 2). Considering the distribution with respect to anatomical quadrants, erosions were mainly located in the radial sides of both the $\mathrm{MCH} 2$ and 3 (figure 2). Also, when erosions were examined in terms of volumes, performing the measurement on the biggest visible erosion in each compartment (target erosion), the two groups did not significantly differ (table 2). Notably, no relationship was found between the burden of enthesiophytes and that of erosions in the patient group $(r=-0.119, \mathrm{p}=0.39)$.

Inter-observer agreement for the detection of erosions as well as enthesiophytes ranged from high to very high. $\kappa$ Coefficient accounted for 0.95 for erosion $(p<0.001)$ and 0.66 for enthesophytes $(\mathrm{p}<0.001)$. For enthesiophytes size, inter-observer agreement was high $(r=0.89, \mathrm{p}<0.001)$. Intraobsever agreement for bony protrusions had previously been tested (SK) and was high $(r=0.97, p<0.001) .^{23}$ For erosions, intrareader reliability (DS) was high as well $(\mathrm{r}=0.91, \mathrm{p}<0.001)$.

\section{DISCUSSION}

Joint involvement is a frequent complication of psoriatic skin disease. Skin disease usually precedes joint disease and some clinical characteristics such as scalp and nail involvement have been associated with a higher risk of developing PsA. ${ }^{24}$ Early recognition of joint disease in psoriasis patients, especially the detection of PsA, is of seminal importance as it allows timely initiation of appropriate treatment and assures favourable clinical and functional outcome of this severe and chronic joint disease. $^{25-27}$ In this manuscript, we provide evidence that structural joint changes, that is, bone modelling at the entheses, can be observed even in the absence of PsA providing evidence for structural joint alterations already at the time of apparently exclusive skin involvement in psoriatic disease.

While the diagnosis of PsA according to the CASPAR criteria represents a definite clinical proof for the presence of musculoskeletal disease in psoriasis patients, more subtle changes may start before the diagnosis of PsA and may be found in a substantially larger proportion of psoriasis patients than those affected by PsA. This concept of a subclinical joint involvement in psoriasis patients is not completely new and has earlier been referred to as 'occult PsA'. ${ }^{28}$ In fact, MRI and ultrasound examination of
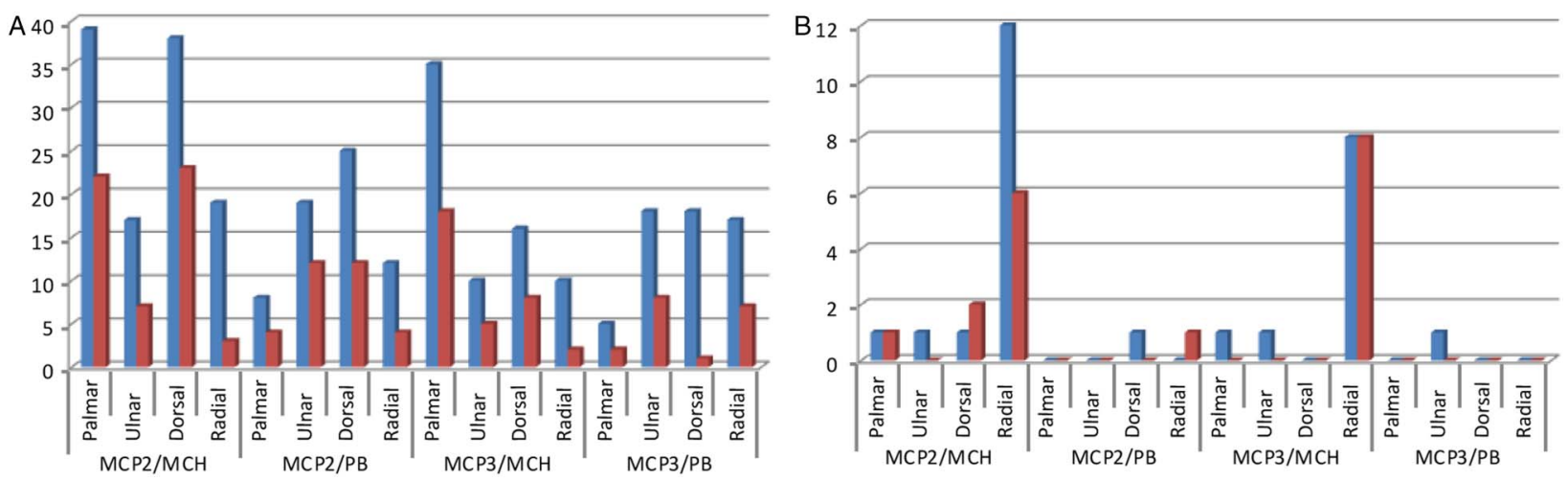

Figure 2 Anatomical distribution of erosions and enthesiophytes. (A) Enthesiophytes in psoriasis patients (blue bars) and healthy controls (red bars); $\mathrm{MCH}$, metacarpal head; $\mathrm{PB}$, phalangeal base; $\mathrm{MCP}$, metacarpophalangeal joint. (B) Erosions in psoriasis patients (blue bars) and healthy controls (red bars). 


\section{Clinical and epidemiological research}
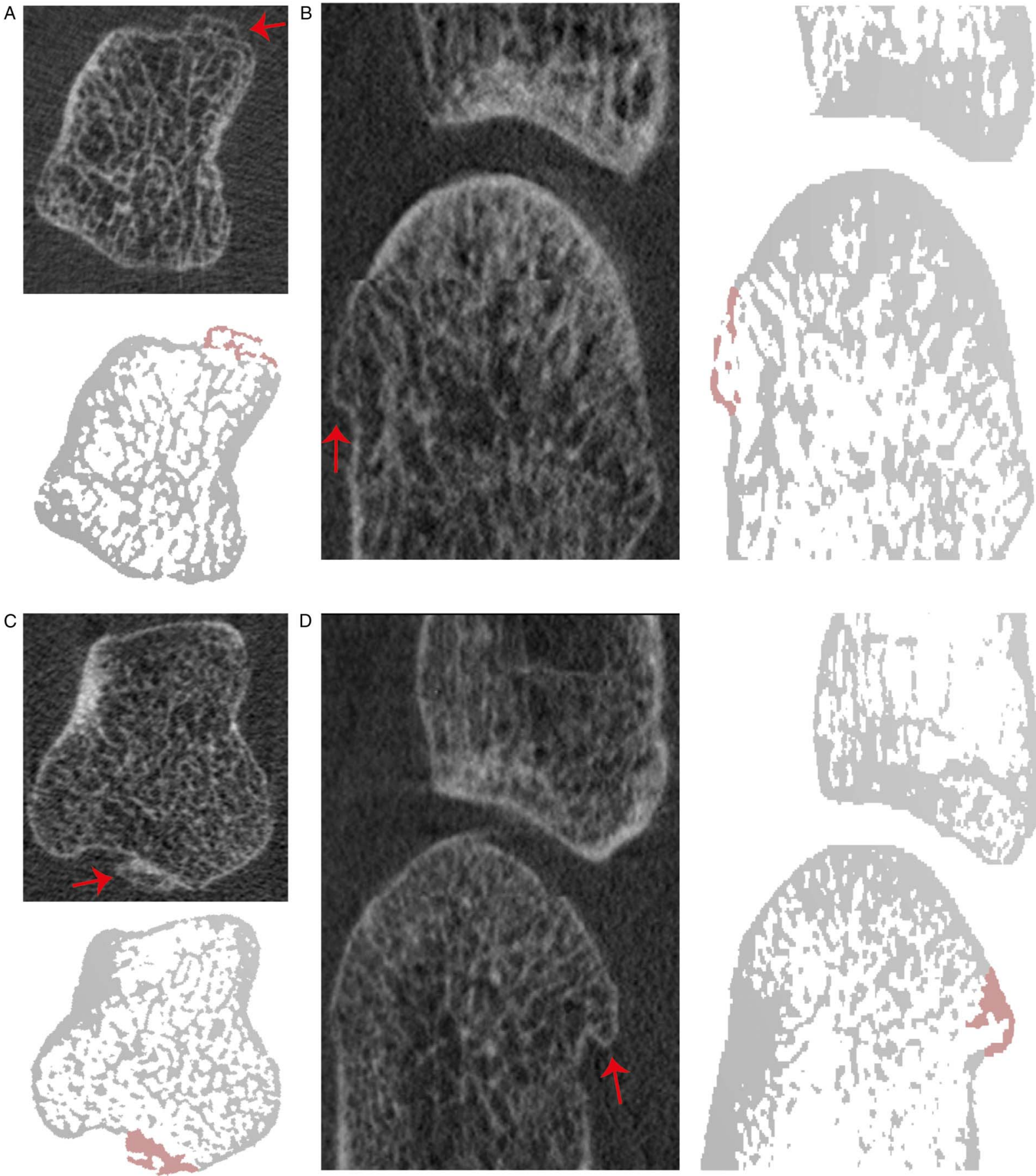

Figure 3 Examples of enthesiophyte formation at areas of functional entheses. (A and B) Axial and sagittal views of a metacarpal head showing new bone formation at the dorsal side. ( $C$ and $D)$ Axial and sagittal views of a metacarpal head showing new bone formation at the palmar side.

the joints of patients with psoriasis substantiated this concept revealing signs of subclinical synovitis and enthesitis in the absence of PsA. ${ }^{9} 290$ Although these studies suggest that subclinical inflammation exists to some extent in the joints of a subset of psoriasis patients, they are usually cross-sectional and the findings need further confirmation in longitudinal studies. Such considerations however are in accordance with concepts in RA, showing that inflammatory changes can be found in patients with autoantibodies but no diagnosis of RA. ${ }^{31}$

In our study, we searched for changes of the bone microstructure in psoriasis patients using HR-pQCT as an imaging tool allowing high-quality analysis of the bone in humans. ${ }^{13} 23 \mathrm{We}$ thereby focused on patients with no present or past signs of joint manifestations to stringently rule out clinical joint involvement. Importantly, the key structural signal we obtained in patients with psoriasis was not bone erosions but enthesiophyte formation. This finding is interesting and reinforces the pathogenic role of the entheses in patients with psoriatic disease. Apparently, entheseal changes can occur in the sole presence of skin disease and do not require the clinical arthritis corroborating the concept of an intrinsic clinical connection between the skin and the entheses, which has been previously suggested by molecular studies referring to the role of interleukin-23 as a linker between skin and entheseal pathology. ${ }^{32}$ At this point, it 
Table 2 Periarticular bone changes in the psoriasis patients and healthy controls

\begin{tabular}{|c|c|c|c|c|c|}
\hline & Psoriasis patients & & Healthy controls & & p Value* \\
\hline Number of subjects & 55 & & 47 & & \\
\hline Erosions total, $\mathrm{N}$ & 27 & & 18 & & \\
\hline Erosions/patient, $\mathrm{N}$ & 0.5 & & 0.4 & & \\
\hline Erosions, mean $\pm S D$ & $0.49 \pm 0.94$ & & $0.39 \pm 0.65$ & & 0.99 \\
\hline Metacarpal head $2 \mathrm{~N}(\%)$ & $15(55)$ & & $9(50)$ & & \\
\hline Phalangeal base $2 \mathrm{~N}(\%)$ & $1(4)$ & & $1(6)$ & & \\
\hline Metacarpal head $3 \mathrm{~N}(\%)$ & $10(37)$ & & $8(44)$ & & \\
\hline Phalangeal base $3 \mathrm{~N}(\%)$ & $1(4)$ & & $0(0)$ & & \\
\hline Enthesiophytes total, $\mathrm{N}$ & 306 & & 138 & & \\
\hline Enthesiophytes/patient, N & 6 & & 3 & & \\
\hline Enthesiophytes, mean \pm SD & $5.62 \pm 3.30$ & & $3.04 \pm 1.81$ & & $<0.001$ \\
\hline Metacarpal head 2, N (\%) & $113(37)$ & & $55(40)$ & & \\
\hline Phalangeal base $2, \mathrm{~N}(\%)$ & $64(21)$ & & $32(24)$ & & \\
\hline Metacarpal head 3, N (\%) & $71(23)$ & & $33(23)$ & & \\
\hline \multirow[t]{2}{*}{ Phalangeal base $3, \mathrm{~N}(\%)$} & $58(19)$ & & $18(13)$ & & \\
\hline & Mean \pm SD & Min-Max & Mean \pm SD & Min-Max & \\
\hline \multicolumn{6}{|l|}{ Total volume (Erosions)† } \\
\hline Metacarpal head $2\left(\mathrm{~mm}^{3}\right)$ & $1.95 \pm 0.94$ & $0.25-6.10$ & $2.54 \pm 3.77$ & $0.23-11.97$ & 0.76 \\
\hline Phalangeal base $2\left(\mathrm{~mm}^{3}\right)$ & 5.2 & 5.2 & 0.27 & 0.27 & $-\ddagger$ \\
\hline Metacarpal head $3\left(\mathrm{~mm}^{3}\right)$ & $3.21 \pm 2.37$ & $0.26-7.45$ & $2.87 \pm 2.31$ & $0.33-6.66$ & 0.88 \\
\hline Phalangeal base $3\left(\mathrm{~mm}^{3}\right)$ & 0.28 & 0.28 & - & - & - \\
\hline \multicolumn{6}{|c|}{ Total height (enthesiophytes)† } \\
\hline Metacarpal head 2 (mm) & $1.68 \pm 0.78$ & $0.54-3.69$ & $1.20 \pm 0.47$ & $0.45-2.04$ & $<0.001$ \\
\hline Phalangeal base 2 (mm) & $1.27 \pm 0.72$ & $0.43-3.14$ & $0.73 \pm 0.27$ & $0.30-1.42$ & 0.001 \\
\hline Metacarpal head 3 (mm) & $1.19 \pm 0.56$ & $0.40-3.30$ & $0.78 \pm 0.34$ & $0.44-1.72$ & 0.005 \\
\hline Phalangeal base 3 (mm) & $1.18 \pm 0.71$ & $0.39-3.88$ & $0.76 \pm 0.20$ & $0.40-1.04$ & $<0.001$ \\
\hline
\end{tabular}

must remain open if enthesiophyte formation is triggered by phases of subclinical inflammation in these patients or if other more biomechanically triggered events precipitate new bone formation. The observation that enthesiophytes were not related to erosions and that erosions did not differ between psoriasis patients and healthy controls may support the latter concept. However, we did not find a relation between enthesiophytes and BMI, which is typically elevated in psoriasis patients. ${ }^{33}$

We also considered that the higher prevalence of obesity among the patients could be related to an increased prevalence of osteoarthritis (OA). However, the use of HR-pQCT allowed us to define the exact localisation of the new bone formation at the enthesial sites rather than at the joint margins. Osteophytes defined as bony spurs at the joint margin were virtually absent in this cohort since the mean age of the patients was rather low, ruling out primary OA, and since the patients did not have PsA, ruling out the development of secondary OA. ${ }^{34}$

Entheses, but also the skin, are sites exposed to biomechanical stress and repeated micro-traumatic injury. These complex anatomical structures are made to adjust and dissipate mechanical loads. ${ }^{35}$ In the peripheral joints, entheses can be found at the attachment of the collateral ligaments and the circumferential insertion of the capsule itself, which are also known as 'synovio-entheseal complexes' and are highly prone to structural bone changes. ${ }^{15} 36$ Furthermore, functional entheses exist such as the dorsal and palmar sites of the MCHs serving as pulleys for the extensor and flexor tendons, respectively. ${ }^{21}$ Importantly, these mechanically exposed locations were identical with the sites of new bone formation, suggesting a tight connection between mechanical factors and the bone response observed in psoriasis patients. Our findings provide new evidence for the existence of a Deep Koebner Phenomenon at the entheseal sites of psoriasis patients. ${ }^{37-39}$ In its original description, ${ }^{40}$ this phenomenon corresponds to the trigger of inflammation and acro-osteolysis by a discrete traumatic injury. Our findings extend the concept of the Deep Koebner Phenomenon suggesting a pathological tissue response to mechanical stress in psoriasis patients. This response affects the mechanically exposed sites of the body, which are the skin and the entheses.

The specific importance of enthesiophyte formation in psoriasis patients is also supported by the observation that the burden of bone erosions was not significantly enhanced in psoriasis patients compared with healthy controls. Although a numerical difference was found between psoriasis patients and controls, differences with respect to enthesiophytes were much more pronounced, suggesting entheseal but not erosive changes as the primary structural event in patients with psoriatic disease. Furthermore, bone erosions strictly followed the distribution pattern previously described in healthy controls as well as in pathological conditions ${ }^{3641}$ which was again confirmed in this study. Formation of bone erosions may indeed require a higher level of local inflammation and hence may emerge later during subclinical or clinical inflammation in psoriasis and PsA patients. In particular, bone erosions require osteoclast differentiation which highly depends on a local inflammatory environment, ${ }^{42}$ whereas enthesiophytes may also occur in the absence of inflammation. ${ }^{43}$ 
In summary, psoriasis is associated with new bone formation at entheseal sites even if PsA is absent. These data shed a new light on the interaction between the skin and the joint suggesting similarities between the skin and the entheseal organs in their aberrant response to stress in patients with psoriasis.

Contributors DS, FF, AK, JH, SK, AJH, RK and MS collected the data. DS, FF, ME, AJH, GS and JR analysed and interpreted the data. DS, FF, GS and JR prepared and revised the manuscript.

Funding This study was supported by the Deutsche Forschungsgemeinschaft (SPP1468-IMMUNOBONE), the Marie Curie project OSTEOIMMUNE, the TEAM and MASTERSWITCH projects of the European Union, the IMI-funded project BTCure and the Pfizer Competitive Grant Award Germany. The present work was performed in fulfilment of the requirements for obtaining the doctoral degree 'Dr. med.' for David Simon.

Competing interests None.

Patient consent Obtained.

Ethics approval University of Erlangen-Nuremberg Ethics Committee.

Provenance and peer review Not commissioned; externally peer reviewed.

\section{REFERENCES}

1 Scarpa R, Ayala F, Caporaso N, et al. Psoriasis, psoriatic arthritis, or psoriatic disease? J Rheumatol 2006;33:210-12.

2 Catanoso M, Pipitone N, Salvarani C. Epidemiology of psoriatic arthritis. Reumatismo 2012;64:66-70.

3 Leonard DG, O'Duffy JD, Rogers RS. Prospective analysis of psoriatic arthritis in patients hospitalized for psoriasis. Mayo Clin Proc 1978;53:511-18.

4 Gelfand JM, Gladman DD, Mease PJ, et al. Epidemiology of psoriatic arthritis in the population of the United States. J Am Acad Dermatol 2005;53:573.

5 McGonagle D, Ash Z, Dickie L, et al. The early phase of psoriatic arthritis. Ann Rheum Dis 2011;70(Suppl 1):i71-6.

6 Taylor W, Gladman D, Helliwell P, et al. Classification criteria for psoriatic arthritis: development of new criteria from a large international study. Arthritis Rheum 2006; 54:2665-73.

7 Emad Y, Ragab Y, Gheita T, et al. Knee enthesitis and synovitis on magnetic resonance imaging in patients with psoriasis without arthritic symptoms. J Rheumatol 2012;39:1979-86.

8 Freeston JE, Coates LC, Nam JL, et al. Is there subclinical synovitis in early psoriatic arthritis? A clinical comparison with gray-scale and power Doppler ultrasound. Arthritis Care Res (Hoboken) 2014;66:432-9.

9 Naredo E, Moller I, de Miguel E, et al. High prevalence of ultrasonographic synovitis and enthesopathy in patients with psoriasis without psoriatic arthritis: a prospective case-control study. Rheumatology (Oxford) 2011;50:1838-48.

10 Torre Alonso JC, Rodriguez Perez A, Arribas Castrillo JM, et al. Psoriatic arthritis (PA): a clinical, immunological and radiological study of 180 patients. $\mathrm{Br} J$ Rheumatol 1991;30:245-50.

11 Gladman DD, Shuckett R, Russell ML, et al. Psoriatic arthritis (PSA)—an analysis of 220 patients. Q J Med 1987;62:127-41.

12 Gladman DD, Stafford-Brady F, Chang CH, et al. Longitudinal study of clinical and radiological progression in psoriatic arthritis. J Rheumatol 1990;17:809-12.

13 Finzel S, Englbrecht M, Engelke K, et al. A comparative study of periarticular bone lesions in rheumatoid arthritis and psoriatic arthritis. Ann Rheum Dis 2011;70:122-7.

14 Kacar C, Sezer I, Kocabas H, et al. Sacroiliac joint involvement in psoriasis. Rheumatol Int 2010;30:1263-6.

15 McGonagle D, Lories RJ, Tan AL, et al. The concept of a "synovio-entheseal complex" and its implications for understanding joint inflammation and damage in psoriatic arthritis and beyond. Arthritis Rheum 2007;56:2482-91.

16 Benjamin M, McGonagle D. The anatomical basis for disease localisation in seronegative spondyloarthropathy at entheses and related sites. I Anat 2001:199:503-26.

17 Benjamin M, McGonagle D. Histopathologic changes at "synovio-entheseal complexes" suggesting a novel mechanism for synovitis in osteoarthritis and spondylarthritis. Arthritis Rheum 2007;56:3601-9.
18 Fredriksson T, Pettersson U. Severe psoriasis—oral therapy with a new retinoid. Dermatologica 1978;157:238-44.

19 Finlay AY, Khan GK. Dermatology Life Quality Index (DLQI)—a simple practical measure for routine clinical use. Clin Exp Dermatol 1994;19:210-16.

20 Stach CM, Bauerle M, Englbrecht M, et al. Periarticular bone structure in rheumatoid arthritis patients and healthy individuals assessed by high-resolution computed tomography. Arthritis Rheum 2010;62:330-9.

21 Milz S, Putz R, Ralphs JR, et al. Fibrocartilage in the extensor tendons of the human metacarpophalangeal joints. Anat Rec 1999;256:139-45.

22 Albrecht $\mathrm{A}$, Finzel $\mathrm{S}$, Englbrecht $\mathrm{M}$, et al. The structural basis of MRI bone erosions: an assessment by microCT. Ann Rheum Dis 2013;72:1351-7.

23 Finzel S, Kraus S, Schmidt S, et al. Bone anabolic changes progress in psoriatic arthritis patients despite treatment with methotrexate or tumour necrosis factor inhibitors. Ann Rheum Dis 2013;72:1176-81.

24 Wilson $\mathrm{FC}$, Icen $\mathrm{M}$, Crowson $\mathrm{CS}$, et al. Incidence and clinical predictors of psoriatic arthritis in patients with psoriasis: a population-based study. Arthritis Rheum 2009:61:233-9.

25 Araujo EG, Finzel S, Englbrecht M, et al. High incidence of disease recurrence after discontinuation of disease-modifying antirheumatic drug treatment in patients with psoriatic arthritis in remission. Ann Rheum Dis 2013.

26 Gossec L, Smolen JS, Gaujoux-Viala C, et al. European League Against Rheumatism recommendations for the management of psoriatic arthritis with pharmacological therapies. Ann Rheum Dis 2012;71:4-12.

27 Ritchlin CT, Kavanaugh A, Gladman DD, et al. Treatment recommendations for psoriatic arthritis. Ann Rheum Dis 2009;68:1387-94.

28 Palazzi C, Lubrano E, D'Angelo $S$, et al. Beyond early diagnosis: occult psoriatic arthritis. J Rheumatol 2010;37:1556-8.

29 Gisondi P, Tinazzi I, El-Dalati G, et al. Lower limb enthesopathy in patients with psoriasis without clinical signs of arthropathy: a hospital-based case-control study. Ann Rheum Dis 2008;67:26-30.

30 Offidani A, Cellini A, Valeri G, et al. Subclinical joint involvement in psoriasis: magnetic resonance imaging and X-ray findings. Acta Derm Venereol 1998:78:463-5.

31 Gent YY, Wee MM, Dowling C, et al. Three year clinical outcome following baseline magnetic resonance Imaging of anti-citrullinated protein antibody-positive arthralgia patients: an explorative study. Arthritis Rheumatol 2014;66:2909-10.

32 Sherlock JP, Joyce-Shaikh B, Turner SP, et al. IL-23 induces spondyloarthropathy by acting on ROR-gammat+ CD3+CD4-CD8- entheseal resident T cells. Nat Med 2012;18:1069-76.

33 Sommer DM, Jenisch S, Suchan $\mathrm{M}$, et al. Increased prevalence of the metabolic syndrome in patients with moderate to severe psoriasis. Arch Dermatol Res 2006;298:321-8

34 Finzel S, Sahinbegovic E, Kocijan R, et al. Inflammatory bone spur formation in psoriatic arthritis is different from bone spur formation in hand osteoarthritis. Arthritis Rheumatol 2014;66:2968-75.

35 Benjamin M, Moriggl B, Brenner E, et al. The "enthesis organ" concept: why enthesopathies may not present as focal insertional disorders. Arthritis Rheum 2004:50:3306-13.

36 McGonagle D, Tan AL, Moller Dohn U, et al. Microanatomic studies to define predictive factors for the topography of periarticular erosion formation in inflammatory arthritis. Arthritis Rheum 2009;60:1042-51.

37 Jacques $P$, Lambrecht $S$, Verheugen $E$, et al. Proof of concept: enthesitis and new bone formation in spondyloarthritis are driven by mechanical strain and stromal cells. Ann Rheum Dis 2014;73:437-45.

38 McGonagle D, Thomas RC, Schett G. Spondyloarthritis: may the force be with you? Ann Rheum Dis 2014;73:321-3.

39 Hsieh J, Kadavath S, Efthimiou P. Can traumatic injury trigger psoriatic arthritis? A review of the literature. Clin Rheumatol 2014;33:601-8.

40 Moll JM, Wright V. Psoriatic arthritis. Semin Arthritis Rheum 1973;3:55-78.

41 Poggenborg RP, Bird P, Boonen A, et al. Pattern of bone erosion and bone proliferation in psoriatic arthritis hands: a high-resolution computed tomography and radiography follow-up study during adalimumab therapy. Scand I Rheumatol 2014:43:202-8.

42 Diarra D, Stolina M, Polzer K, et al. Dickkopf-1 is a master regulator of joint remodeling. Nat Med 2007;13:156-63.

43 Lories RJ, Luyten FP, de Vlam K. Progress in spondylarthritis. Mechanisms of new bone formation in spondyloarthritis. Arthritis Res Ther 2009;11:221. 


\section{A Analysis of periarticular bone changes in patients with cutaneous psoriasis without associated psoriatic arthritis}

David Simon, Francesca Faustini, Arnd Kleyer, Judith Haschka, Matthias Englbrecht, Sebastian Kraus, Axel J Hueber, Roland Kocijan, Michael Sticherling, Georg Schett and Jürgen Rech

Ann Rheum Dis2016 75: 660-666 originally published online February 4, 2015

doi: 10.1136/annrheumdis-2014-206347

Updated information and services can be found at:

http://ard.bmj.com/content/75/4/660

These include:

References This article cites 42 articles, 12 of which you can access for free at: http://ard.bmj.com/content/75/4/660\#ref-list-1

Email alerting service

Receive free email alerts when new articles cite this article. Sign up in the box at the top right corner of the online article.

Topic Articles on similar topics can be found in the following collections

Collections

Degenerative joint disease (4641)

Musculoskeletal syndromes (4951)

\section{Notes}

To request permissions go to:

http://group.bmj.com/group/rights-licensing/permissions

To order reprints go to:

http://journals.bmj.com/cgi/reprintform

To subscribe to BMJ go to:

http://group.bmj.com/subscribe/ 